\title{
Amplitude térmica para germinação de conídios de Drechslera tritici-repentis
}

\author{
Rosane Baldiga Tonin ${ }^{1}$; Camila Ranzi ${ }^{1}$; Juliane Nicolodi Camera ${ }^{1}$; Carlos Alberto Forcelini ${ }^{1,2}$ \& Erlei Melo Reis ${ }^{1,2}$.
}

${ }^{1}$ Faculdade de Agronomia e Medicina Veterinária, Departamento de Fitossanidade - Universidade de Passo Fundo - UPF, 99001, Passo Fundo, RS, Brasil. ${ }^{2}$ Professor da FAMV/PPGAgro/UPF.

Autor para correspondência: Rosane Baldiga Tonin (rosanetonin@yahoo.com.br)

Data de chegada: 07/04/2013. Aceito para publicação em: 16/06/2014.

$10.1590 / 0100-5405 / 1881$

\section{RESUMO}

Tonin, R.B.; Ranzi, C.; Camera, J.N.; Forcelini, C.A.; Reis, E.M. Amplitude térmica para germinação de conídios de Drechslera tritici-repentis. Summa Phytopathologica, v.40, n.2, p.174-177, 2014.

\begin{abstract}
A mancha-amarela do trigo, causada pelo fungo Drechslera tritici-repentis, é de ocorrência mundial e uma das principais doenças da cultura. No Brasil, a mesma está presente em todas as safras e pode reduzir o rendimento de grãos em mais de $40 \%$. A sua ampla adaptabilidade a ambientes diversos pode estar relacionada à capacidade dos esporos germinarem sob diferentes temperaturas, assunto que foi examinado neste experimento conduzido na UPF, em 2011. Suspensões de conídios $(350 \mu \mathrm{L})$ foram depositadas em placas de Petri com meio ágar-água e incubadas em câmara tipo BOD, na presença e ausência de luz, a $-5,0,5,10,15,20,25,30,35$ e $40^{\circ} \mathrm{C}$, por $2,4,6,8$ e 10 horas. $O$ trabalho foi
\end{abstract}

conduzido duas vezes, em delineamento inteiramente casualizado, com quatro repetições. Os conídios germinaram tanto na presença como na ausência de luz. A germinação foi nula a $-5^{\circ} \mathrm{C}$ ou $40^{\circ} \mathrm{C}$. A mesma foi detectada após $2 \mathrm{~h}$ e aumentou com o tempo de incubação. Através de polinômios de segundo grau estimou-se a máxima germinação a $19^{\circ} \mathrm{C}$ e $9,5 \mathrm{~h}$ de incubação. Houve predominância da germinação bipolar (frequência de $45,0 \%$ ), seguida da intercalar $(33,5 \%)$ e da unipolar (21,5\%). Os resultados obtidos indicam grande amplitude térmica para germinação dos conídios de D. tritici-repentis, o que explica, parcialmente, sua ampla distribuição geográfica.

Palavras-chave adicionais: Triticum aestivum, mancha-amarela, esporos, regimes de luz

\section{ABSTRACT}

Tonin, R.B.; Ranzi, C.; Camera, J.N.; Forcelini, C.A.; Reis, E.M. Temperature range for conidial germination by Drechslera tritici-repentis. Summa Phytopathologica, v.40, n.2, p.174-177, 2014.

Tan spot, caused by the fungus Drechslera tritici-repentis, is of worldwide occurrence and one of them main diseases affecting the wheat culture. In Brazil, tan spot is present in every crop season and may reduce grain yield by more than $40 \%$. The great adaptability of this disease to diverse environments may be related to the capability of spores to germinate at different temperatures, which was examined in this experiment conducted at UPF, in 2011. Conidial suspensions $(350 \mu \mathrm{L})$ were placed onto Petri plates containing water-agar medium and incubated in a BOD-type chamber, in the presence and absence of light, at $-5,0,5,10,15,20,25,30,35$ and $40^{\circ} \mathrm{C}$, during $2,4,6,8$ and 10 hours.
The experiment was conducted twice, in a completely randomized design, with four replicates. Conidia germinated either in the presence or in the absence of light. Germination was null at $-5^{\circ} \mathrm{C}$ or $40^{\circ} \mathrm{C}$. It was detected after $2 \mathrm{~h}$ and increased with the incubation time. Second-degree polynomials were used to estimate maximum germination at $19^{\circ} \mathrm{C}$ and $9.5 \mathrm{~h}$ of incubation. There was predominance of bipolar germination (frequency of $45.0 \%$ ), followed by intercalar (33.5\%) and unipolar (21.5\%) germination. The obtained results showed a large temperature range for $D$. tritici-repentis conidial germination, which may partially explain the widespread distribution of this fungus.

Additional keywords: Triticum aestivum, tan spot, spores, light regimes.

A cultura do trigo (Triticum aestivum L.) está sujeita ao ataque de vários patógenos causadores de manchas foliares que, dependendo da intensidade podem causar reduções significativas no rendimento de grãos da cultura (12).

A mancha-amarela do trigo encontra-se distribuída em mais de 21 países (10) sendo considerada uma doença cosmopolita. Foi relatada como doença importante na Austrália (13), no Canadá (20) e nos Estados Unidos (8). No Brasil, a primeira referência sobre o agente causal foi no Rio Grande do Sul, em 1959 (4). A partir do ano de 1979, a mancha-amarela aumentou de intensidade, especialmente em função da semeadura direta, e atualmente é uma das doenças foliares mais frequentes em trigo (10).
Seu agente causal, o fungo Drechslera tritici-repentis Died., sobrevive, principalmente, em sementes e restos culturais, a partir dos quais infecta as folhas causando lesões primárias. Nessas manchas o fungo produz novos esporos, disseminados pelo vento até as folhas ou plantas vizinhas, originando ciclos secundários da doença (17).

As condições ambientais ideais para o desenvolvimento da manchaamarela incluem temperaturas entre 18 e $28^{\circ} \mathrm{Ce}$ período de molhamento igual ou superior a $30 \mathrm{~h}(15)$. A temperatura age como catalisador dos processos biológicos, razão pela qual tanto as plantas como os patógenos requerem uma temperatura mínima e máxima para crescer e desenvolver normalmente suas atividades (16).

Apesar da importância da doença, a literatura sobre aspectos da 
fisiologia do fungo em relação à amplitude térmica e temperatura ótima para a germinação dos conídios é escassa. Esse tipo de informação é relevante para o entendimento da distribuição da doença, assim como para a sua previsão através do monitoramento climático.

Neste sentido, os objetivos desse trabalho foram: (i) determinar o tipo de germinação de conídios do fungo, (ii) identificar a amplitude térmica e o tempo necessário para sua ocorrência e (iii) verificar o efeito da luminosidade no referido processo.

\section{MATERIAL E MÉTODOS}

Os experimentos foram conduzidos no Laboratório de FitopatologiaMicologia da Faculdade de Agronomia e Medicina Veterinária da Universidade de Passo Fundo/UPF, no ano de 2011.

O isolado monospórico de $D$. tritici-repentis foi obtido a partir de folhas com sintomas da doença, coletadas em lavoura comercial de trigo BRS Guamirim, no município de Coxilha-RS. Discos de 5 mm de diâmetro foram cortados das lesões e desinfetados em solução aquosa de hipoclorito de sódio (1\%) por três minutos, e após lavados três vezes com água destilada para retirar o excesso do desinfetante. Os fragmentos foram distribuídos em caixas de acrílico, tipo gerbox, contendo espuma de nylon e duas folhas sobrepostas de papel de filtro, saturadas com água destilada e esterilizada, formando uma câmara úmida. As caixas foram mantidas a temperatura de $25^{\circ} \mathrm{C}$ e fotoperíodo de $12 \mathrm{~h}$. Após cinco dias, com o auxílio de uma agulha histológica flambada, estruturas do patógeno foram transferidas para placas de Petri contendo meio de cultura semi-seletivo de Reis (14).

Após obtenção das colônias induziu-se a esporulação do patógeno, como a seguir: primeiramente, discos de $5 \mathrm{~mm}$ de diâmetro, obtidos de colônias puras do fungo, foram transferidos para placas com meio de cultura V8-ágar e incubados em BOD (Biological Oxygen Demand), a $25^{\circ} \mathrm{C}$ e escuro contínuo por cinco dias. Então as colônias foram cobertas com água destilada e esterilizada e pressionadas suavemente com a base de um tubo de ensaio. $\mathrm{O}$ excesso de água foi removido e as placas novamente incubadas a $25^{\circ} \mathrm{C}$, desta vez sob regime de luz contínua por $24 \mathrm{~h}$. Após esse período a incubação foi então alterada para $15^{\circ} \mathrm{C}$ e escuro contínuo por outras $24 \mathrm{~h}$.

Os conídios formados foram removidos com auxílio de pincel de pelo de camelo número 20, obtendo-se a suspensão de esporos em água, da qual uma alíquota de $300 \mu \mathrm{L}$ foi vertida em placas de Petri $(60$ x 15 $\mathrm{mm}$ ) contendo o meio ágar-água (6). As placas foram incubadas a $20^{\circ} \mathrm{C}$, durante seis horas, sob luz contínua. Com o auxílio de microscópio óptico, em magnitude de 100 vezes, observou-se a germinação dos conídios. Com uma espátula esterilizada foram cortados pequenas porções de meio de cultura ágar-água contendo um único conídio germinado e transferidos para placas de Petri contendo meio de cultura BDA e incubadas até o crescimento das colônias puras do fungo.

A partir das culturas puras, preparou-se uma suspensão de conídios, dessa suspensão foram pipetados $350 \mu \mathrm{L}$ em placas de Petri, tamanho $60 \times 15 \mathrm{~mm}$, contendo o meio ágar-água. No estudo foram avaliadas as temperaturas de $-5,0,5,10,15,20,25,30,35$ e $40^{\circ} \mathrm{C}$ e tempos de exposição de 2, 4, 6, 8 e 10h. As placas foram mantidas em BOD, exposta à luz contínua e escuro contínuo, sendo as de escuro contínuo envolvidas com papel alumínio. Decorrido o tempo desejado, a germinação foi interrompida com a adição de $350 \mu \mathrm{L}$ de uma solução de solução de acetona (100\%) com corante azul de algodão, em cada placa de Petri. Este procedimento foi realizado para cada tempo, com e sem presença de luz, submetido às diferentes temperaturas.

Determinou-se a germinação através da quantificação, ao acaso, de
50 conídios por repetição, pela varredura da placa, num microscópio óptico (Olympus CX 31) em magnitude de 40 vezes. Considerou-se germinado, o conídio que apresentou o tubo germinativo mais longo do que sua maior largura (21).

O tipo da germinação dos conídios foi classificado de acordo com Seaman et al. (19), com modificação: i) unipolar, quando o pró-micélio ou tubo germinativo foi formado apenas na base ou no ápice do conídio; ii) bipolar, pró-micélio ou tubo germinativo no ápice e na base; e iii) intercalar, pró-micélio ou tubo germinativo na base ou no ápice e em alguma célula intercalar do conídio. Com auxílio de microscópio óptico, foram analisados 200 conídios, formados a $19^{\circ} \mathrm{C}$, na presença de luz, após $10 \mathrm{~h}$ de incubação.

Os dois ensaios foram organizados em delineamento inteiramente casualizado, com quatro repetições, cada unidade experimental representada por uma placa de Petri. São apresentados os dados médios dos dois experimentos. A temperatura ótima para a geminação dos conídios foi calculada através da média dos resultados obtidos pela fórmula da regressão de cada um dos tempos testados. O limiar térmico inferior e superior foram as temperaturas, nas quais não se observou a germinação dos conídios de $D$. tritici-repentis. Os dados obtidos foram submetidos à análise de variância e de regressão.

\section{RESULTADOS E DISCUSSÃO}

A germinação dos esporos do fungo ocorreu tanto na presença como na ausência de luz e foi influenciada significativamente pela temperatura de incubação. Pelos dados originais, a germinação foi nula a $-5^{\circ} \mathrm{C}$ e $40^{\circ} \mathrm{C}$, e máxima a $20^{\circ} \mathrm{C}$. Os polinômios obtidos por análise de regressão apresentaram coeficientes de determinação $\left(\mathrm{R}^{2}\right)$ de 0,9289 (escuro) e 0,9359 (com luz), indicando que a variação de temperatura influenciou em mais de $90 \%$ a germinação. Tanto os dados originais como os modelos matemáticos para incubação no escuro ou sob luz não diferiram significativamente entre si ( $>>0,05)$, mostrando que o fator luminosidade não influencia a germinação dos conídios. Pelos mesmos modelos, a germinação máxima foi estimada na temperatura de $19^{\circ} \mathrm{C}$.

Em relação ao tempo de incubação, a germinação já foi detectada após duas horas e aumentou proporcionalmente até $10 \mathrm{~h}$. O máximo foi estimado após $9,5 \mathrm{~h}$ de incubação. Novamente, não houve efeito significativo $(\mathrm{p}>0,05)$ da luminosidade.

As equações para germinação de conídios em função da temperatura e do tempo de incubação foram integralizadas na Figura 3. Embora a germinação máxima tenha sido estimada para a combinação de $19^{\circ} \mathrm{C}$ x 9,5h, há uma ampla faixa de temperatura e tempo de incubação favorável à germinação. Por exemplo, a partir de $15^{\circ} \mathrm{C}$ e $4 \mathrm{~h}$ de incubação a germinação foi superior a $60 \%$.

Os resultados obtidos neste trabalho indicam grande amplitude térmica para germinação dos conídios de D. tritici-repentis. Portanto, a temperatura não deve ser o principal fator limitante à ocorrência da mancha-amarela nas lavouras de trigo no Sul do Brasil. Em Passo Fundo, por exemplo, nos meses de julho a outubro, quando a cultura encontra-se em desenvolvimento no campo, a temperatura média histórica varia de 13,3 a $17,6^{\circ} \mathrm{C}(5)$.

Conforme reportado por Reis et al. (18) a distribuição geográfica da mancha-amarela não é limitada pelo clima, sendo a mesma tão importante em países como Austrália, Canadá, Estados Unidos, Brasil, Paraguai e Uruguai. Mesmo nas regiões tritícolas brasileiras, nota-se que a doença tem importância semelhante desde o Paraná até o Rio Grande do Sul. A germinação de esporos adaptada a uma vasta gama de temperaturas explica parcialmente a distribuição mundial do fungo 


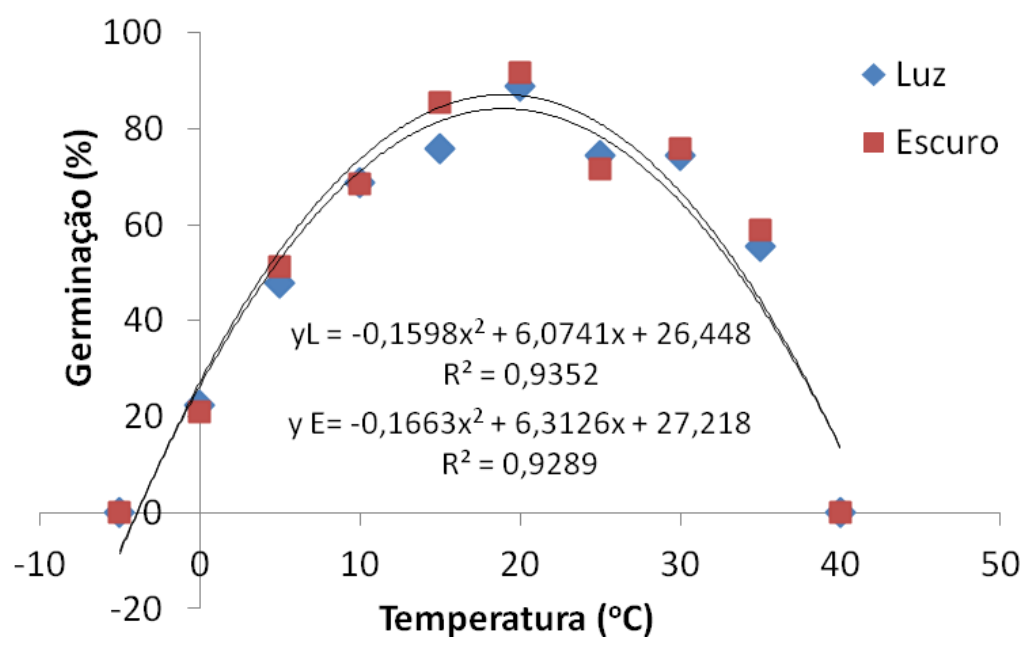

Figura 1. Germinação de conídios de Drechslera tritici-repentis em função da temperatura de incubação e da exposição à luz. Passo Fundo, RS. 2011.

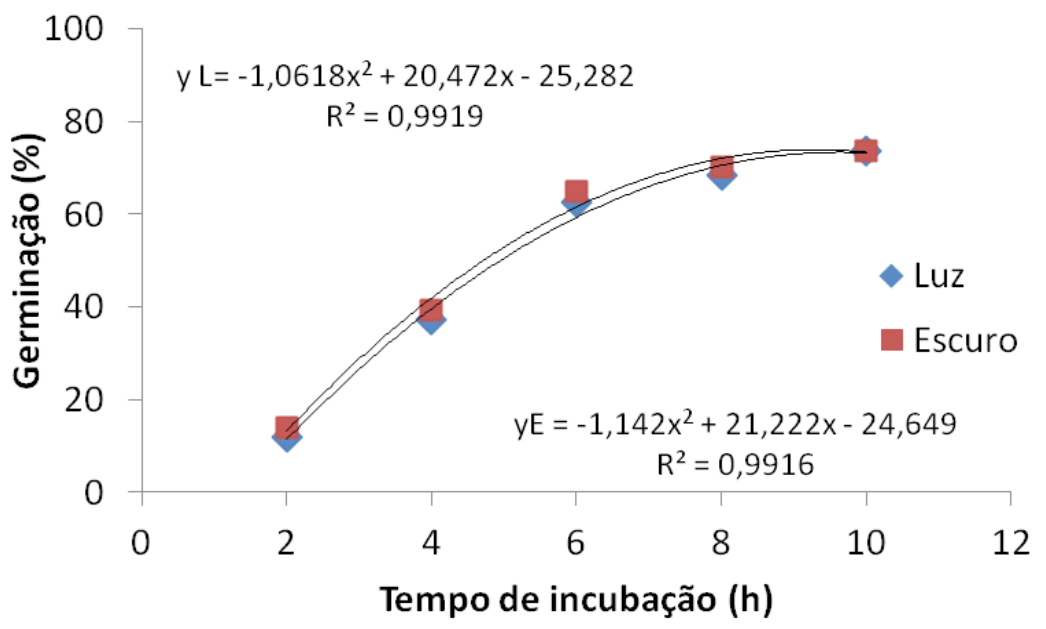

Figura 2. Germinação de conídios de Drechslera tritici-repentis em função do tempo de incubação e da exposição à luz. Passo Fundo, RS. 2011.

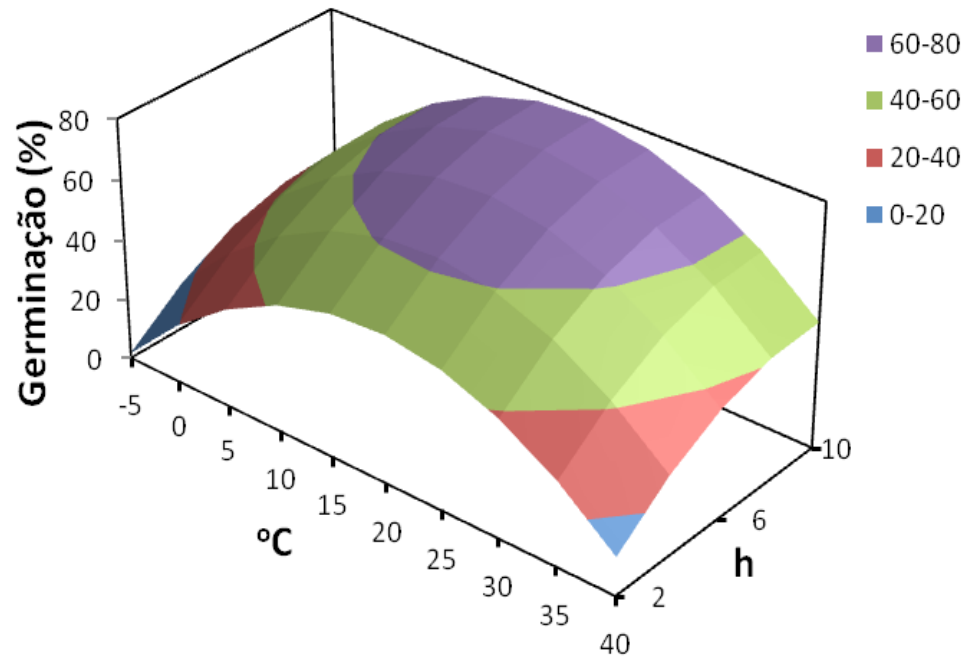

Figura 3. Germinação de conídios de Drechslera tritici-repentis em função da interação entre temperatura e tempo de incubação. Médias dos dados obtidos com e sem exposição à luz. Passo Fundo, RS, 2011. 


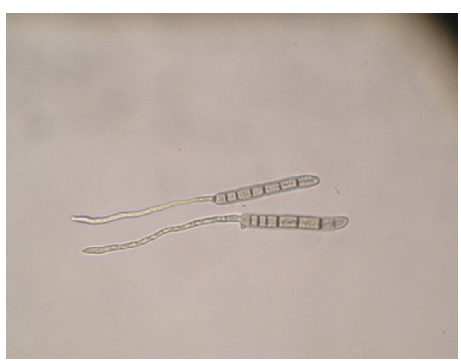

i) Unipolar $(21,5 \%)$

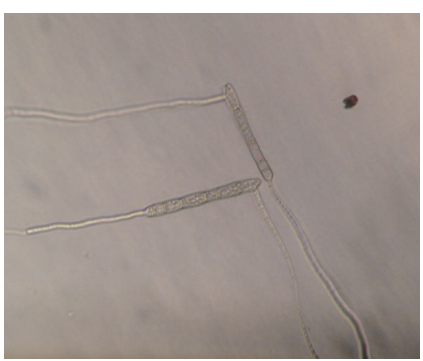

ii) Bipolar $(45,0 \%)$

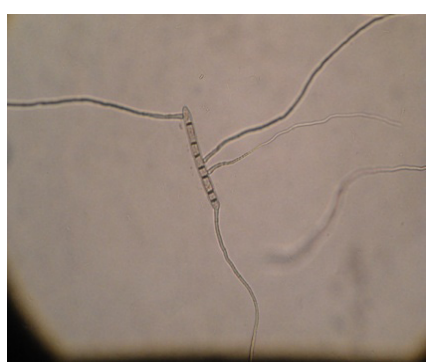

iii) Intercalar $(33,5 \%)$

Figura 4. Tipo e frequência de germinação dos conídios de Drechslera tritici-repentis incubados a $19^{\circ} \mathrm{C}$, por 10 horas, com exposição à luz. Passo Fundo, RS, 2011.

\section{D. tritici-repentis.}

Limites amplos de temperatura para germinação de esporos também foram observados em outros patossistemas, como 0 e $40^{\circ} \mathrm{C}$ para Cercospora sojina Hara (3), 0 e 40,4 ${ }^{\circ} \mathrm{C}$ para Corynespora cassiicola (Berk. \& Curtis) Weir (7) e 6 e $35^{\circ} \mathrm{C}$ para Phakopsora pachyrhizi Sydow (9), todos em soja.

Outro ponto favorável à germinação dos conídios deste fungo é a sua independência do fator luminosidade, sendo, assim diferente de Puccinia triticina, agente causal da ferrugem da folha do trigo. Para este fungo, a temperatura ótima para a germinação dos esporos nas raças MDK-MR (B55 4002S) e MCG-MN (B34) foi menor no escuro $\left(8,9\right.$ e $\left.10,8^{\circ} \mathrm{C}\right)$ e maior sob luz $\left(18,5\right.$ e $\left.16,2^{\circ} \mathrm{C}\right)(2)$.

Outro fator demonstrado neste trabalho foi o tipo de germinação apresentado pelos conídios de $D$. tritici-repentis, que pode ser unipolar (frequência de $21,5 \%)$, bipolar $(45,0 \%)$ ou intercalar $(33,5 \%)$. De acordo com descrição feita por Mitra (11), apud Reis et al. (18), é comum a emissão de tubos germinativos a partir de todas as células do conídio, e algumas vezes, dois ou mais tubos germinativos de uma única célula. Segundo Alcorn (1), o tipo de germinação do conídio é critério importante para diferenciar o gênero Drechslera.

As informações obtidas neste trabalho indicam predominância da forma bipolar de germinação dos conídios de D. tritici-repentis, assim como a grande amplitude térmica na qual os esporos podem germinar. Essa capacidade contribui para sua adaptação a diferentes condições de ambiente, e pode explicar a ocorrência e importância da mancha-amarela nas principais regiões tritícolas do mundo. Essa mesma amplitude térmica dificulta o desenvolvimento de sistemas de previsão para a doença com base no monitoramento de variáveis ambientais.

\section{REFERÊNCIAS BIBLIOGRÁFICAS}

1. Alcorn, J. L. The taxonomy of "Helminthosporium" species. Annual Review of Phytopathology, v. 26, p.37-56, 1988.

2. Bianchin, V. Especialização fisiológica de Puccinia triticina, agressividade e sensibilidade de raças a fungicidas. 2011. $131 \mathrm{f}$. Tese (Doutorado em Agronomia)-Universidade de Passo Fundo, Passo Fundo/RS.

3. Camera, J. N. Patogenicidade, esporulação e interação entre temperatura e período de molhamento foliar na intensidade da mancha foliar “olho-de-rã" em soja. 2012. 101 f. Dissertação (Mestrado em Agronomia)-Universidade de Passo Fundo, Passo Fundo.

4. Costa Neto, J.P. Fungos observados em gramíneas e leguminosas no Rio
Grande do Sul. Revista da Faculdade de Agronomia e Veterinária. Porto Alegre, p. 51-67, 1967.

5. Embrapa Trigo. Normais climatológicas. Passo Fundo, 2013. Disponível em: <www.cnpt.embrapa.br/ pesquisa/agromet/app/principal/normais $>$. Acesso em 14 fev. 2013.

6. Fernandez, M.R. Manual para laboratório de fitopatologia. Passo Fundo: EMBRAPA-CNPT, 1993. 128 p. (Documentos, 6).

7. Ferreira Filho, A.S. Caracterização morfológica e enzimática de isolados de Corynespora cassiicola e reação de cultivares de soja à mancha-alvo. 2012. 84 f. Dissertação (Mestrado em Agronomia) - Universidade de Passo Fundo, Passo Fundo.

8. Hosford, R.M. Jr., Tan spot. In: Hosford, R.M. Jr.(Ed.). Tan spot of wheat and related diseases workshop. Fargo, North Dakota State University, 1982. p.1-24.

9. Marchetti, M.A., Melching, J.S., Bromfield, K.R. The effects of temperature and dew period on germination and infection by uredospores of Phakopsora pachyrhizi. Phytopatology, Sait Paul, v. 66, p. 461-463, 1976.

10. Metha, Y.R. Manejo integrado de las enfermedades del trigo. Santa CruZ de la Sierra, Imprenta Landivar, Bolívia, 1993. 319p.

11. Mitra, M.A. Leaft spot disease of wheat caused by Helmintosporium triticirepentis Died. Indian Journal of Agricultural Science, Índia, v.4, p. 692-700,1934.

12. Picinini, E.C.; Fernandes, J.M.C. Ensaios preliminares e cooperativos de fungicidas - resultados obtidos no Centro Nacional de Pesquisa de Trigo no período 1988 - 1991. Passo Fundo: Embrapa- Centro Nacional de Pesquisa de Trigo, 1992. 28 p.

13. Rees, R.G.; Platz, G.J. The occurrence and control of yellow spot of wheat in North-Eastern Australia. Australian Journal Exp. Agricultural Anim. Husb. Austrália, v.19: p. 369-372, 1979.

14. Reis, E.M. Selective medium for isolating Cochliobolus sativus from soil. Plant Disease, St. Paul, v.67, p.68-70,1983.

15. Reis, E.M.; Casa, R.T.; Medeiros, C.A. Diagnose, patometria e controle de Doenças de cereais de Inverno. Londrina: E. S. Comunicação S/C Ltda, 2001. $94 \mathrm{p}$.

16. Reis, E.M. Previsão de doenças de plantas. Passo Fundo: Editora UPF, 2004, $316 \mathrm{p}$.

17. Reis, E.M.; Casa, R.T. Doenças do trigo (Triticum aestivum L.). In: Kimati, H.; Amorim, L.; Rezende, J.A.M.; Bergamin Filho, A.; Camargo, L.E.A. Manual de Fitopatologia. Doenças das Plantas Cultivadas. p. 631-638, 2005. 4 ed. São Paulo Agronômica Ceres, São Paulo, 2005. Vol. 2.

18. Reis, E.M.; Casa, R.T.; Danelli, A.L.D. Doenças do trigo - Mancha-amarela da folha. $2^{0}$ ed Passo Fundo: Bayer CropScience. 2011. 18p

19. Seaman, W.L.; Shoemaker, R.A.; Peterson, E.A. Pathogenicity of Corynespora cassiicola on soybean. Canadian Journal of Botany, Canadá. v.43, p. 1461-1469, 1965.

20. Wright, K.H.; Sutton, J.C. Inoculum of Pyrenophora tritici-repentis in relation to epidemics of tan spot of winter wheat in Ontario. Canadian Journal of Plant Pathology. Canadá. v. 12, p.149-157, 1990.

21. Zadoks, J.C.; Schein, R.D. Epidemiology and plant disease management. New York: Oxford University Press, 1979. 427p. 